\title{
TAX EVASION IN SALES CUTS REGISTERED BY ELECTRONIC CASH REGISTER
}

Tax evasion is a persistent problem of public finances. Sales cuts registered by electronic cash register (hereinafter referred to as „ECR") is part of tax evasion. The State, through constant changes in legislation, creates barriers against them, which are effective only in the short term. The paper is based on the documentation of administrative offences arising from demands and communications with the financial administration. It analyses the changes in the law relating to the elimination of tax evasion by recording sales of ECR and evaluates them. It applies a model approach for the identification of subjects and links in the system. Risky relationships between subjects are exposed and menas of their elimination are proposed. It emphasises the important position of ICT in ECR, identifies difficult places in hardware and software, and suggests areas for improvement.

Keywords: Tax evasion, electronic cash register (ECR), sales records, tax legislation, tax regulation.

\section{Introduction}

European Union countries, including Slovakia, on the one hand, fight with government deficits; while on the other hand, admit the inefficiency of tax collection and massive tax evasion. The European Commission estimates that as a result of tax evasion and tax avoidance, Member States lose millions of Euros a year ${ }^{1}$. The Slovak Republic, with its estimated tax evasion of around $4 \%$ of GDP ${ }^{2}$ significantly contributes to these losses. One of the ways of how to solve state budget deficits and public debt is the fight against tax evasion and tax fraud. Tax avoidance is defined as lawful minimisation of tax liability through legal methods of modifying income, whereas tax evasion represents the illegal practice [1]. Illegal tax evasion may take the form of "tax fraud in the concealment of some of the assets of the taxpayer, tax malversation in the concealment of income that may arise, for example, in the denial of sales or overestimation of tax expenditure" [2]. A number of measures against tax evasion are supported by information and communication technologies which are used for the collection, storage, use and share of information on national and international level, the creation of electronic documents, but also the creation of other instruments, such as electronic cash registers.

${ }^{1}$ www.euractiv.sk CEurActiv 2003-2014

${ }^{2}$ http://spravy.pravda.sk/ekonomika/clanok/293659-danove-uniky-naslovensku-v-roku-2011-dosiahli-28-miliardy-eur/

\section{The reasons for the introduction and development of Electronic Cash Registers.}

The main reason for introduction of electronic cash registers

The Slovak Republic introduced the use of electronic cash registers in March 1994 by the Decree of the Ministry of Finance of the Slovak Republic no. 55/1994 on the Method of Keeping Sales Records by an Electronic Cash Register. The purpose was either to ensure the correct collection of corporate income tax which conceded cash receipts from sales of goods and some services enlisted as enumerative in Decree, or to ensure consistent organised records of the VAT payer in cash payments and unambiguous determination of the simplified invoice for VAT purposes.

\section{Development of electronic cash registers - first period}

ECR was defined in the Decree as "electronic register or electronic register weight device equipped with a printer for the calculation and registration of figures entered by keyboard or electronic reading of a bar code or magnetic cards, or other means." There could be used only such type of cash register for which authorised person issued a certificate confirming the statutory requirements of cash register. It was a relatively simple device which registered turnovers and secured the printing of cash receipts, control tapes, daily and monthly reports. Cash register was placed into service by service organisation the subject of

\footnotetext{
* Maria Durisova, Beata Holkova, Michal Lekyr

Faculty of Management and Informatics, University of Zilina, Slovakia

E-mail: maria.durisova@fri.uniza.sk
} 
charge had a contract with and which was required to register every record in the book of the cash register. Employees of the tax authorities carried out local inspection of the use of ECR in business premises of the taxpayer. Tax administrator also used the records, control tapes and balances for the purposes of tax search on personal or corporate income tax and value added tax. Annually, it was a few thousands of cash register inspections, in 2007 - 2009, more than 16000 local inspections per year ${ }^{3}$, which confirmed that the cash registers are not sufficient barrier against tax evasion in receiving cash receipts. "With new technology we ${ }^{3}$ Source: Finance Directorate of the Slovak Republic use new tools to satisfy ancient needs and learn to use them with our limited cognitive capabilities" [3].

\section{Development of electronic cash registers - second period}

Development in information and communication technologies has overcome many times the options of ECR defined in Decree no. 55/1994, and the Ministry of Finance tried to project this fact into a brand new Act which was adopted as the Act no. 289/2008 on the Use of Electronic Cash Register. There were defined such technical parameters and resources of the cash register which

Data of an ECR inspection in $2012-2014$

Table 1

\begin{tabular}{|c|c|c|c|}
\hline Year & Number of ECR inspections & Number of inspections with findings of the offence & Percentage of inspections with findings \\
\hline 2012 & 5494 & 5101 & $93 \%$ \\
\hline 2013 & 14756 & 7660 & $52 \%$ \\
\hline to 01.10 .2014 & 17552 & 5453 & $31 \%$ \\
\hline
\end{tabular}

Source: Finance Directorate of the Slovak Republic

Data on administrative offences from the use of ECRs in 2012 - 2014

Table 2

\begin{tabular}{|c|c|c|c|c|}
\hline $\begin{array}{l}\text { Administrative } \\
\text { offence under } \\
\text { Section 16a } \\
\text { letter }\end{array}$ & Description of an administrative offence & $\begin{array}{l}\text { Number of } \\
\text { violations of } \\
\text { the law in } \\
2012\end{array}$ & $\begin{array}{l}\text { Number of } \\
\text { violations of } \\
\text { the law } \\
\text { in } 2013\end{array}$ & $\begin{array}{l}\text { Number of } \\
\text { violations of } \\
\text { the law up } \\
\text { to } 31.10 .2014\end{array}$ \\
\hline A & $\begin{array}{l}\text { fails to use an ECR for recording sales revenues or create a document } \\
\text { which is not a cash receipt }\end{array}$ & 1464 & 2004 & 1656 \\
\hline $\mathrm{b}$ & puts an ECR out of operation by its own intervention & 44 & 17 & 2 \\
\hline $\mathrm{c}$ & sales revenues recorded by an ECR do not comply with the requirements & 188 & 248 & 113 \\
\hline d & fails to hand over a sales slip - receipt & 57 & 116 & 39 \\
\hline e & registers sales revenues but fails to hand over a cash receipt & 1208 & 1351 & 234 \\
\hline $\mathrm{f}$ & cash receipt does not comply with the requirements of the law & 355 & 706 & 280 \\
\hline $\mathrm{g}$ & does not have an ECR book placed at the point of sale & 451 & 639 & 247 \\
\hline $\mathrm{h}$ & fails to record the cash deposit in the ECR & 467 & 1151 & 703 \\
\hline $\mathrm{i}$ & $\begin{array}{l}\text { fails to use an ECR in accordance with the law or fails to comply with the } \\
\text { requirements of the law }\end{array}$ & 17 & 244 & 214 \\
\hline $\mathrm{k}$ & fails to ensure the performance of the obligatory ECR maintenance & 918 & 2195 & 2 \\
\hline 1 & $\begin{array}{l}\text { fails to register records on return the goods, negative items and the } \\
\text { discount provided }\end{array}$ & 90 & 415 & 161 \\
\hline $\mathrm{m}$ & fails to indicate the title of the goods or service on cash receipt & 36 & 43 & 1747 \\
\hline $\mathrm{n}$ & $\begin{array}{l}\text { fails to hand over a cash receipt to the buyer when returning the goods or } \\
\text { complaint }\end{array}$ & 18 & 159 & 180 \\
\hline $\mathrm{p}$ & fails to keep the data in an ECR & 13 & 4 & 29 \\
\hline q & $\begin{array}{l}\text { fails to notify the servicing organisation of a damage, malfunction, missing } \\
\text { seal of an ECR }\end{array}$ & 31 & 266 & 105 \\
\hline $\mathrm{r}$ & fails to record receipts in the ECR recordings & 12 & 67 & 4 \\
\hline $\mathrm{t}$ & fails to prepare closing reports of an ECR & 8 & 9 & 79 \\
\hline $\mathrm{u}$ & does not maintain an ECR book in accordance with the law & 33 & 150 & 80 \\
\hline
\end{tabular}

Source: Finance Directorate of the Slovak Republic 
should prevent arbitrary interventions of businessmen in cash register and adjustments already recorded in the cash receipts. The most significant changes from the previously applicable legislation are: storage of data recorded in the cash register into the fiscal memory and prevent their subsequent modification by subject of charge, verifying the authenticity of the data by means of technical equipment of cash register, security feature in the bill, the possibility of obtaining the data stored in the fiscal memory of cash register by control authorities and through another device for that purpose lent by manufacturer, importer, distributor of cash register, securing cash register against unauthorised intervention of the taxpayer by a special seal with protective elements, required maintenance of cash register by service organisations registered in the register of service organisations to the tax office, the definition of administrative offences in connection with violations of the Act on ECRs specifying penalties and fines.

The Act no. 289/2008 was adopted by the National Council of the Slovak Republic in 2008. As the entities had been already using the ECRs, the enforcement of the Act was postponed up to 01.01.2012. The Act enforcement helped the business environment to detect vulnerability of hardware, software and links between the subjects involved in the system of recording sales through ECRP. Inspections of compliance with the new Act on ECRs in 2012 made by the tax authorities pointed out that $93 \%$ of subjects inspected in 2012 violated the new applicable law and probably reduced their taxes, particular data provided in Table 1.

According to the data we have obtained from Finance Directorate of the Slovak Republic (hereinafter "FR SR"), these are the main violations of the Act no. 289/2008 as amended, as are shown in Table 2. In contains the most frequent administrative offences, that are the base of the proposal for lowering these risks.

Finance administration is not able to check all taxpayers and all ECR they use (the number shown in Table 3) because the centre of the work of tax auditor is to check properly quantified and granted tax liability for a specific tax for the year. Implementing local surveys and ECR check is only one of the many related activities carried out by the tax auditor.

Number of ECR registered in the Slovak Republic

Table 3

\begin{tabular}{|c|c|}
\hline Actual state & Number of ECR registered in SR \\
\hline 31.12 .2012 & 256670 \\
\hline 31.12 .2013 & 263429 \\
\hline 03.11 .2014 & 247751 \\
\hline
\end{tabular}

Source: Finance Directorate of the Slovak Republic

When recording the ECR sales revenues there are not only cuts to corporate or personal income tax that collect sales revenues in cash, but many of these tax payers are value added tax payers as well. According to the available statistical information provided by FD SR, more than $60 \%$ taxpayers using ECR are value added tax payers as well.

Data on the number of VAT payers of subjects using ECR Table 4

\begin{tabular}{|c|c|c|c|}
\hline $\begin{array}{c}\text { Actual } \\
\text { state }\end{array}$ & $\begin{array}{c}\text { Number of tax } \\
\text { payers using } \\
\text { ECRs }\end{array}$ & $\begin{array}{c}\text { Number of } \\
\text { VAT payers }\end{array}$ & $\begin{array}{c}\text { Percentage of the } \\
\text { VAT payers of the } \\
\text { total tax subjects } \\
\text { using ECRs }\end{array}$ \\
\hline 31.12 .2012 & 143620 & 88450 & $62 \%$ \\
\hline 31.12 .2013 & 148390 & 90221 & $61 \%$ \\
\hline 03.11 .2014 & 141135 & 86796 & $62 \%$ \\
\hline
\end{tabular}

Source: Finance Directorate of the Slovak Republic

Based on the foregoing facts, it can be stated that the fiscal cash registers did not meet the expectations and prevent tax evasion and tax cuts. It is necessary to identify the reasons that may result from the failure of hardware, software, or subjects involved in ECR sales records.

\section{Model approach to ECR sales records}

Model represents a simplification of economic reality using the means of expressions selected. It abstracts away from irrelevant facts and emphasises the essence. ECR model permitting the elimination of the outflow of sales revenues records is based on the identification of bottlenecks that can be defined in the area: legislation, ECR software and hardware - exclusion of the possibility of subsequent ECR data manipulation, on-line access control data to the tax authorities through information networks, human factor, tax authorities.

\subsection{Model of the ECR sales records under the Act no. 289/2008}

Under applicable Act 289/2008 effective since 2008, sales records using ECR originally formed a comprehensive system of subjects and relationships among them as defined in Fig. 1.

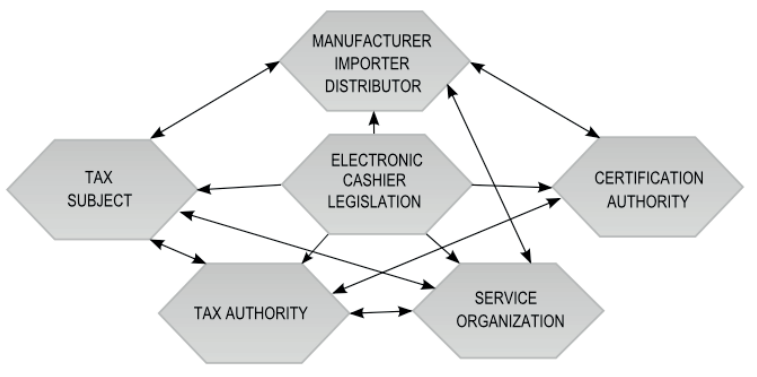

Fig. 1 Model of ECR sales records 
The subjects of ECR sales record model include: ECR legislation, tax subject, manufacturer, salesperson and importer of the ECR, tax administrator, service organisation and certification body. ECR legislation is the content of the Act no. 289/2008 Coll. on the Use of Electronic Cash Register and on the amendment of the Act of the Slovak National Council No. 511/1992 Coll. on Administration of Taxes and Fees and on changes in the system of territorial financial authorities as amended by later regulations. For the purposes of the Act, tax subject - entrepreneur - is a legal or natural person who is required to register on ECRs cash receipts for the sale of goods or services provided in the territory of the Slovak Republic. Manufacturer, salesperson and importer of the ECR is a natural or legal person who places an ECR on the market and is obliged by law to certificate the facilities accredited by the person. In accordance with the law, a person is required to allow the tax administrator to obtain information from the fiscal memory on the basis of application. For the purpose of using ECR, tax administrator is defined as a tax office and customs office that registers ECR, assigns the tax code and makes record in a cash register book. He is also entitled to make audit over the compliance of the law on the use of ECRs by an entrepreneur, to secure cash register in suspected counterfeiting of ECR data, to grant sanctions or give a proposal to cancel ECR business in case of breach of the Act. Service organisation is a natural or legal person who based on the business authorisation can provide repair and maintenance of ECRs and has concluded contract with manufacturer, importer or distributor of ECR on providing repairs and maintenance of ERCs. It must be registered in the register of service organisations kept by tax office. Certification body - person accredited issues a certificate of compliance with the ECR requirements established by the law and takes also into account the technical documentation of the process of agreement assessment, which declares the fulfilment of technical requirements. For the purpose of recording sales revenues pursuant to the Act no. 289/2008, it is possible to use only certified ECR.

The links among the subjects involved in the system of recording sales using ECR can be identified in Fig. 1. The links representing potential risk for the circumvention of the law and tax cuts include, in particular, the links among:

- manufacturers, importers, distributors and accredited person - certification body. Certification shall be carried out for payment on the basis of the business relationship. There were two legal subjects accredited among which there is a competitive relationship. The law does not control whether the certificate cash register complies with the statutory requirements, and whether it is possible to alter any data intercepted.

- manufacturer, importer, distributor and tax subject who buys the ECR. It is the business relationship between the seller and the buyer. It is natural that the seller is trying to deliver a product to market that would meet the expectations of the buyer and the buyer is more interested in a flexible ECR, which may modify the data if necessary.

- manufacturer, importer, distributor and service organisation. Service organisation is applying for the contractual relationship with the manufacturer, importer or distributor to carry out repair and maintenance services of certified cash register being placed on the market, and may enter into a contractual relationship with a number of subjects. There are currently 1063 service organisations maintained in the Register of ECR service organisations by the tax office competing in the servicing and maintenance of 247751 ECRs in Slovakia. The success of the business of service organisation also depends on the number of concluded contracts with the manufacturers, importers or distributors of the ECR, therefore it is possible to define this link as risky.

- tax subject and service organisation. Service organisation concludes contractual relationship with the tax subject on the service and maintenance of specific ECR. There are 141135 tax subjects in total that have registered at least one ECR in Slovakia, these tax subjects choose the service organisation of 1063 service organisations registered by the tax office, provided that the service organisation has entered into a contract with the manufacturer, importer or distributor of the cash register of their type. The success of the business of service organisation also depends on customer satisfaction with the services of the service organisation. Therefore, "firms need highly competent workers and growth of human capital quality is very important for them" [4]. In this sense, "one of the possibilities of increasing the competitiveness of companies is to focus on increasing the value of human capital of their employees using company education, which is aimed at increasing job skills, abilities and knowledge" [5]. The services of the service organisation also represent, in addition to repairs and maintenance, the obligation to record the data from the fiscal memory and interventions made into cash book, but also, without delay, report tax office of the breach of seal, changes to the data stored in the ECR, and deviation from the ECR certified by an accredited person. Considering all the links listed there is a relationship of unilateral or mutual economic dependence and therefore there arises a potential tax risk.

\subsection{Model of ECR sales records after the last legislative amendment}

Based on the audit findings of the tax authorities listed in Tables $1-4$ there were adopted legislative changes, the most significant may be considered:

- ECR shall allow on-line connection with the information system of financial administration,

- Introduction of virtual cash register at the web site of FD SR, 
- fiscal memory shall be marked with a unique and unrepeatable code generated by the ECR manufacturer, and this code is printed on destructive sticker, which is affixed in the process of registration to the fiscal memory as well as to the outer cover of the ECR together with ECR product label,

- manufacturer, importer, or distributor of ECR is obliged to provide FD SR with technical and software tools for reading, exporting, and verifying records,

- issuing certificates of compliance with the statutory requirements for electronic cash register will be provided by the Customs Office in Bratislava,

- expansion of activities - services - where the taxpayer is obliged to register sales revenues received in cash through ECR,

- if there is a reasonable suspicion of altering data in ECR or audit records, tax administrator can ensure ECR and issue a decision on ECR forfeiture.

"Legislative factors are the most important factors of tax evasion. Qualitative level of laws is important both at the level of prevention as well as repression. Legislation revised, when particular Acts form interconnected, undisputed unit, undoubtedly contributes to a great extent to the elimination of tax evasion" [6].

The changes affect the model of ECR sales records in terms of stakeholders and the links among them as documented in Fig. 2.

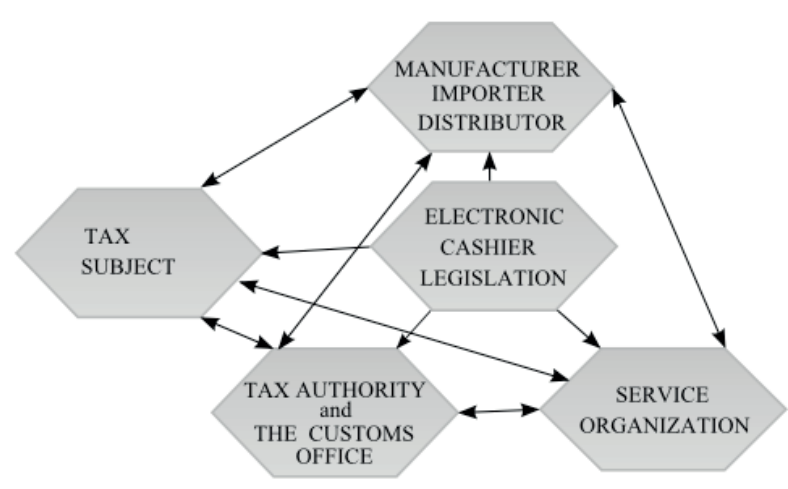

Fig. 2 A modified model of ECR sales records

New legislation has removed risky link among manufacturer, importer, distributor and accredited person - certification body. The certification of the registers will be carried out by the tax administrator - Customs Branch Office in Bratislava. There is an assumption that the cash registers certified will truly comply with the statutory requirements and it will not be possible to alter the data captured in them. Virtual and on-line cash registers connected to information systems of tax administrator should be a benefit for the performance of the tax inspection. The legislation does not say about it, but we assume that data from the connected and virtual cash registers stored on the server of tax administrator will be accessible to the employees of the tax administrator for the purpose of the tax inspection on the income tax and value added tax. These last legislative modifications probably made the collection of taxes on sales recorded through ERP safer.

\section{Hardware and software applied by recording ECR sales}

Sales revenues of the ECR are primarily based on the hardware and software the ECR consists of. The development of information and communication technology is advancing at a rapid pace and is one of the instruments of the reduction in sales. Figure 3 schematically depicts the receiving commands and data, internal control programme, memory for storing fiscal data and sending commands and data exchange from the point of view of complex software for ECR.

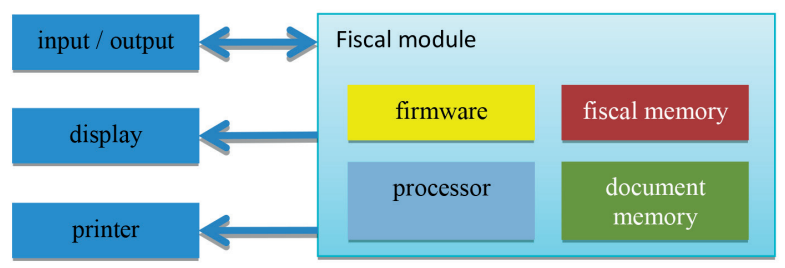

Fig. 3 ECR Hardware and software

Internal control software - firmware, located in the fiscal memory module and its instructions are carried out on the microprocessor, is responsible for decoding the input commands that control programme sends to fiscal printer. Devices communicate using a special language called communication protocol the fiscal printer manufacturer defines. Individual commands are decoded by control programme and direct the activities of the fiscal printer. It is unlikely that the manufacturer of fiscal printer would deliberately implement functionality to control programme allowing to misrepresent tax data. Mistakes in programme that could be discovered by fiscal printer integrator and subsequently diverted to misrepresent tax documentation represent bigger danger.

Standardisation of control commands and limitation of their sets would minimise the risk in this area, and the control programme would not respond to other commands. There must come to a thorough review in this area of the certification authority - there were granted certificates to devices in the past that did not contain even the fiscal module (e.g. FM41, etc.). There would be benefit for the creation of a system for monitoring of firmware update and setting up a system for checking the firmware at the level of source code. We realise, however, that manufacturers constantly improve the control software, implement legislative changes and, therefore, the inspection in this area is very difficult and cumbersome. 
Fiscal memory is considered to be such a memory which is able to store the data entered in the long term and is additionally protected by a protective layer that prevents damage to the hardware section of the memory. Fiscal memory is used to store daily accounts of a fiscal printer. Memory determined for journal is used to store electronic copies of the fiscal documents. It is possible to physically replace the memory in some of these devices for the purpose of its further archiving; some devices have both memories combined into one, and all data written to one memory card.

The main risks in this field include regressive access to data and their retroactive adjustment and subsequent cuts in sales, physical memory failure and the loss of all fiscal data, etc. The first prerequisite for minimising these risks represents appropriate physical security and protection of memory through the seals and protective material. The next step of protection is to implement procedures and use of methods of cryptography and digital data protection in such a way that they cannot be altered, or that any such change is evident. The generation of protective keys and timestamp makes it possible to minimise the possibility of decrypting data and their subsequent changes. Suitable methods ensure that the data are adequately protected against efforts to manipulate them.

\section{Fiscal printer administration from the control computer}

Printer manufacturers leave the communication of control computer with fiscal printer to so-called integrators. They are mostly software developers. Their software uses a part of the fiscal printer and allows businesses to make cash register operations. Each manufacturer has his own ideas about how the communications protocol should work. Some manufacturers import fiscal modules from abroad and adjust them to the needs of the Slovak legislation; others design and implement their own products in Slovakia. The problem is that there is missing a certain standardisation of communication protocols in this area, literally every type of fiscal module can handle a different set of commands and therefore it is very difficult for integrators to integrate a greater number of fiscal printers into their products. In some cases, it is even possible to find several communication protocols for a variety of devices produced by the manufacturer.

In this area, it would be beneficial if the manufacturer supplied communication libraries to his fiscal printers and would not publish a specific communication protocol whose vulnerabilities could be subject to abuse and the subsequent reduction of taxes.

Figure 4 reflects the proposed scheme of communication arrangement.

It is necessary to design and implement communication libraries so that the software can communicate with multiple types of fiscal printers. Control of management applications through these libraries should have a consistent approach to the creation of documents and the implementation of other operations. It is necessary to make a proposal so that the output data from the control programme are independent on a specific communication protocol of the printer.

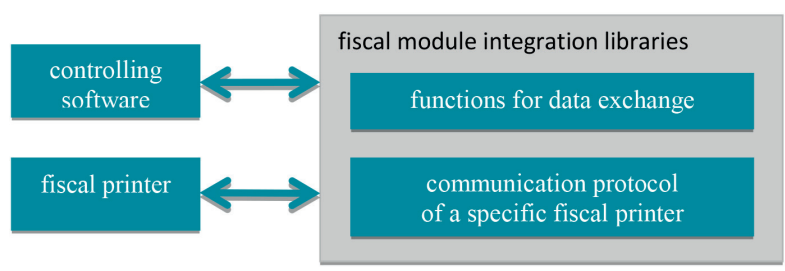

Fig. 4 FM library integration

With thorough analysis of the functioning of the communication protocol it is necessary to maximise the flexibility of code, minimise the redundancy of code and maximise the speed of writing and reading data. The library itself must ensure inside rapid communication with fiscal printer and direct control of date written and read. It should provide for the possibility of reading documents from the fiscal memory and fiscal module journal.

\section{Conclusion}

The results of the analysis of administrative offenses using ECR listed in Table 2 shows the reasons for the breach of fiscal discipline resulting in tax evasion. The primary reason is a conscious act of taxpayers to obtain economic benefits. It also demonstrated that such behaviour of taxpayers is allowed by our ambiguous and unclear legislation.

The research of ECR sales recording primarily pointed out two major problem areas - risk links among subjects and tax morality. The comparison of model 1 and 2 shows that the critical link in the legislation between product, importers, distributors and certification body has been detached. The competences were transferred to the customs office.

The links that are not solved and eliminated by legislation remain those of service organisation with manufacturer, importer, distributor, and service organisation with tax subjects.

Service organisation is the weakest point in the system of relations and subjects in recording cash receipts through the ECR. On the one hand, service organisation is fighting for a customer on the market, and on the other hand, the law directs it to inform tax administrator about its tax sins, if it happens to be its customer. The dilemma of service organisation could be solved by weakening economic relationship between the service organisation and tax subject by:

- cash register service would be provided by the state, or 
- service organisation would be assigned by tax administrator on a random basis, or any other key and price list of service work would be set by the state.

\section{Acknowledgement}

This paper has been written with the support of the European Social Fund, project Innovation and Internationalization of
Education - instruments to increase the quality of the University of Zilina in the European educational area. Modern Education for the Knowledge Society / Project is funded by EU; Grant (granted by Ministry of Education) VEGA No 1/0421/13 Attribute efficiency and the human capital; VEGA 1/0526/13 Modelling of the multilateral relations of economic entities and improving the quality of their decision-making processes with ICT.

\section{References}

[1] SVATKOVA, S.: English: Bachelor Thesis on Taxes (in Czech), Trizonia, 1994, p.155

[2] BIELIKOVA, A., STOFKOVA, K.: Taxes in Theory and Practice (in Slovak), EDIS : University of Zilina, 2010, ISBN978-80-5540169-0, p. 42

[3] TOKARCIKOVA, E.: Influence of Social Networking for Enterprise's Activities, Periodica Polytechnica, Social and Management Sciences, 19/1, 2011, 37-41 doi: 10.3311/pp.so.2011-1.05 - ISSN 1416-3837, p. 39

[4] KUCHARCIKOVA, A.: Investment in the Human Capital as the Source of Economic Growth. Periodica Polytechnica Social and Management Sciences, vol. 22, No. 1, 2014, Hungary, pp. 29-35, ISSN 1587-3803, SCOPUS, p. 33

[5] KUCHARCIKOVA, A.: The Importance of Identification and Analysis of Educational Needs for Investment in Human Capital. Communications - Scientific Letters of the University of Zilina, vol. 16, No. 3, 2014, pp. 86-92, ISSN 1335-4205, SCOPUS, p. 75

[6] KRNAC, M.: The Cause of Tax Evasion and Possibilities of Eliminations by Changing the Criminal Law. Proc. of intern. conference Milniky prava v stredoeuropskom priestore 2012. Univerzita Komenskeho : Bratislava. ISBN 978-80-7160-317-7, p. 593. 